Chem. Soc. Rev., 1987, 16, 313-338

\title{
Product Stability in Kinetically-Controlled Organic Reactions
}

\author{
By Sosale Chandrasekhar \\ DEPARTMENT OF ORGANIC CHEMISTRY, INDIAN INSTITUTE OF SCIENCE, \\ BANGALORE 560012 , INDIA
}

\section{Introduction}

Few organic reactions yield a single product. Therefore, an appreciation of the factors which affect the distribution of products in organic reactions is of great importance. While external variables such as solvent, temperature, catalysts, etc., are expected to be important, it is perhaps natural to wonder whether the stability of a product has any influence on its yield.

Indeed, in a reaction where many products are derived from the same reactant, one may expect (perhaps naively) that changes in transition-state structure are mainly influenced by changes in product structure. On the other hand, the concept of thermodynamic and kinetic control implies that, if anything, the more stable product is formed more slowly. An interesting question which then arises is: 'Just how do most organic reactions behave?'

Many years ago the terms 'product stability control' and 'steric approach control' were invented in connection with the reduction of ketones with complex metal hydrides. Subsequently, however, it was decided that product stability actually had little influence on the course of the reactions, which proceeded via 'early, reactant-like transition states'.

This review addresses the question: 'How general is this phenomenon?' A variety of organic reactions, many of synthetic importance, is so considered in the following sections. Clearly, exhaustiveness is impossible, and the author has, therefore, tried to establish general trends.

Finally, in this section, the following definition is in order. The term 'kineticallycontrolled reaction' is used to mean a reaction which is performed away from equilibrium, i.e. in one direction only. Under such conditions, the relative yield of a product reflects its rate of formation.

\section{Additions to Carbon-Oxygen Double Bonds}

A. Reductions of Aldehydes and Ketones with Complex Metal Hydrides.-Much is known about the stereochemistry of reduction of various cyclic ketones with complex metal hydride reagents. This area has been authoritatively covered by a number of reviews, ${ }^{1-3}$ and only an outline of the findings is given below.

1 H. O. House, 'Modern Synthetic Reactions', Benjamin, Menlo Park, 2nd Edition, 1972, p. 54.

2 J. R. Boone and E. C. Ashby, Top. Stereochem., 1979, 11, 53.

${ }^{3}$ D. C. Wigfield, Tetrahedron, 1979, 35, 449. 
The hydride reduction of unhindered cyclohexanones usually yields the more stable equatorial alcohols. Introduction of sterically-hindering substituents at the 3- and 5-positions in the ring, however, increases the proportions of axial alcohols even to the extent of making these isomers predominant (equations 1 and 2).
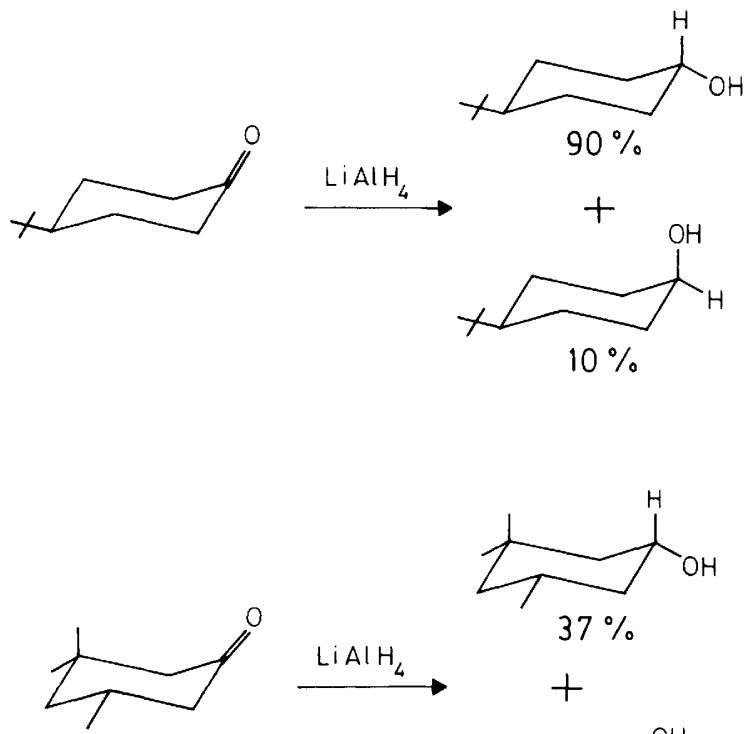

$37 \%$

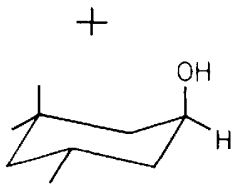

$63 \%$

The accepted explanation is that the predominance of the more stable alcohol is fortuitous and that the stereochemistry of the reduction is mainly controlled by a combination of steric and torsional factors. Formation of the equatorial alcohol requires attack from the axial side of the carbonyl group, where steric interference with the substituents at the 3- and 5-positions in the ring is engendered. However, if these substituents are no larger than hydrogen, it is supposed that such steric interference is less important than the torsional strain involved in equatorial attack. Such strain is thought to arise from the eclipsing of the axial carbon-hydrogen bonds $\alpha$ to the carbonyl group, with the partially-formed bond between the carbonyl carbon atom and the hydride ion.

The reduction of many bicyclic ketones also suggests that product stability is unimportant in determining the course of the reaction. 2-Norbornanone yields predominantly the less stable endo alcohol (equation 3 ).

Similar considerations apply to the reduction of acyclic aldehydes and ketones, with the product stereochemistry being solely determined by factors controlling the 

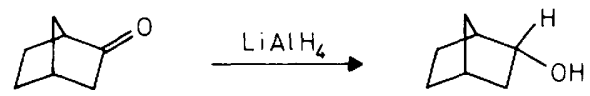

approach of the hydride ion to the carbonyl group. In addition to the steric and torsional factors discussed above, electrostatic factors are also thought to be important in the reductions of acyclic aldehydes and ketones bearing polar substituents. However, assumptions have to be made regarding the orientation of the carbonyl group relative to the $\alpha$-substituents, such orientation usually being unambiguous in cyclic ketones.

The above arguments have been used to explain the Rule of Steric Control of Asymmetric Induction. ${ }^{1}$ According to this rule, the acyclic ketone or aldehyde is considered to react in a conformation in which the carbonyl group is staggered between the medium and the smallest $x$-substituents. The product stereochemistry is then predicted by considering that the hydride ion approaches from the less hindered side of the carbonyl group. Although the relative stabilities of acyclic diastereomers are not easy to predict, it is noteworthy that it is not necessary to invoke product-stability control to explain the course of the reaction.

Rei has made a systematic study of the reaction of various cyclic ketones with lithium aluminium hydride and with methyl lithium. ${ }^{4}$ The above author has made the interesting suggestion that product stereochemistry is governed by a combination of steric strain and product stability. Although such a suggestion had been tried and discarded earlier, it appears to explain the stereochemistry of reduction of cyclopentanones, a reaction in which the more stable trans alcohols predominate.

Ashby and Boone, ${ }^{2,5}$ and Eliel, ${ }^{6}$ however, have questioned the usefulness of the concept of product development control in the reduction of ketones with complex metal hydrides. According to these authors, the stereochemistry of reduction of cyclopentanones is best explained by the 'anti-periplanar' effect. 2-Methylcyclopentanone, for example, is expected to exist in the half-chair conformation (equation 4).

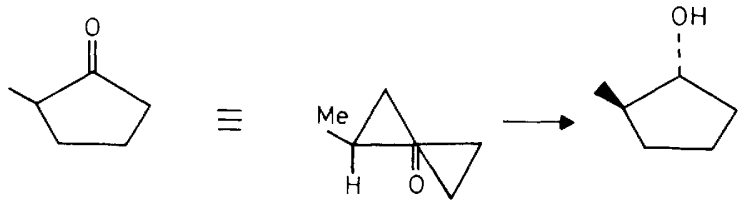

The preference for attack from a direction cis to the methyl group is seen as being due to steric hindrance by the hydrogen on carbon atom 2 to trans attack. Such hindrance is caused by the aforementioned anti-periplanar effect, which is a combination of torsional and orbital distortion effects.

${ }^{4}$ M. Rei, J. Org. Chem., 1979, 44, 2760.

5 E. C. Ashby and S. A. Noding, J. Am. Chem. Soc., 1976, 98, 2010; J. Org. Chem., 1977, 42, 264.

${ }^{6}$ E. L. Eliel and Y. Senda, Tetrahedron, 1970, 26, 2411; D. M. S. Wheeler and M. M. Wheeler, J. Org. Chem., $1962,27,3796$. 
B. Other Reductions of Aldehydes and Ketones.-Both catalytic hydrogenation and the Meerwein-Ponndorf-Verley reduction of cyclohexanones preferentially lead to the axial cyclohexanols, under kinetic conditions. Apparently, in these reactions too, attack takes place from the less hindered, equatorial, side of the carbonyl group. ${ }^{?}$

C. Kinetically-controlled Aldol Condensations.-These reactions show interesting stereochemical results. ${ }^{8}$ The erythro-threo ratios of the aldol products can vary from $0-100 \%$, depending on experimental conditions. However, even when the more stable isomers predominate, product stability is not the cause. The examples in equations 5-7 are illustrative.

It is thought that the erythro-threo ratio is mainly governed by the geometry of the intermediate enolate ion as also by the interactions between the $R^{1}$ and $R^{3}$ groups in the transition state, which is usually of the chair form (Figure 1).

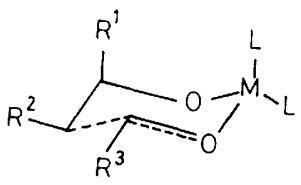

Figure 1

D. The Wittig Reaction.-The Wittig reaction between an aldehyde or a ketone and a phosphorus ylide to yield an olefin, takes place via betaine intermediates, whose formation is usually rate-determining. The nature of these betaine intermediates determines the stereochemistry of the products (Scheme 1) ${ }^{9}$

It is clear from the above scheme that in the absence of thermodynamic control, predominant formation of the erythro betaine (A) would lead to a predominance of the cis olefin. Indeed, cis olefins are preferentially formed in many Wittig reactions. Therefore, there appears to be a kinetic preference for the less stable erythro betaines in these reactions. Either metal cations in the reaction medium or stabilizing $\alpha$-substituents in the ylide can give rise to thermodynamic control. In both cases, thermodynamic control to afford a mixture richer in threo betaine (B) becomes competitive with olefin formation. However, if the Wittig reaction is carried out under conditions favouring kinetic

${ }^{7}$ E. L. Eliel, 'Stereochemistry of Carbon Compounds', McGraw-Hill, New York, 1962, p. 243; H. O. House, 'Modern Synthetic Reactions', Benjamin, Menlo Park, 2nd Edition, 1972, p. 20.

${ }^{8}$ D. A. Evans, J. V. Nelson, and T. R. Taber, Top. Stereochem., 1982, 13, 13; D. Fellmann and J. E. Dubois, Tetrahedron, 1978, 34, 1349; C. H. Heathcock, C. T. Buse, W. A. Kleschick, M. C. Pirrung, J. E. Sohn, and J. Lampe, J. Org. Chem., 1980, 45, 1066; A. I. Meyers and P. J. Reider, J. Am. Chem. Soc., 1979, 101, 2501.

${ }^{9}$ H. O. House, ref. 1, p. 682; M. Schlosser, G. Mueller, and K. F. Christmann, Angew. Chem., Int. Ed. Engl., 1966, 5, 667; M. Schlosser and K. F. Christmann, Annalen, 1967, 708, 1; L. Crombie, P. Hemesley, and G. Pattenden, J. Chem. Soc. (C), 1969, 1016, 1024; O. H. Wheeler and H. N. Battelle de Pabon, J. Org. Chem., 1965, 30, 1473; B. E. Maryanoff, A. B. Reitz, M. S. Mutter, R. R. Inners, and H. R. Almond, Jr., J. Am. Chem. Soc., 1985, 107, 1068. 
<smiles></smiles>

$95 \%$

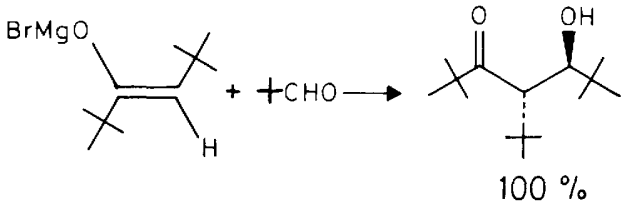<smiles>O=C1CCCCC1[C@H](O)c1ccccc1</smiles>

$52 \%$

$\mathrm{R}^{\prime} \mathrm{CHO}$
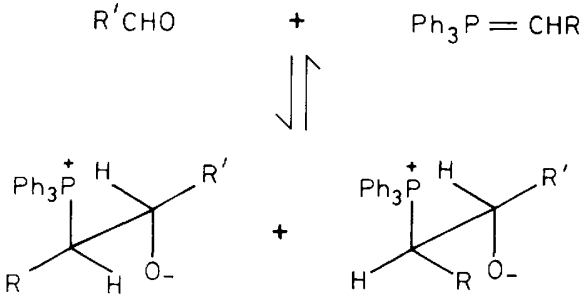

(A)
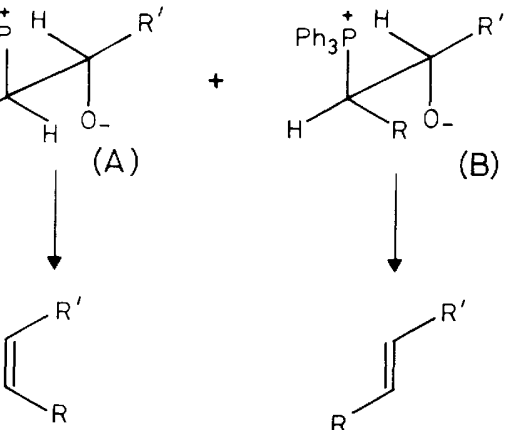

Scheme 1 
control, it is generally found that the less stable cis olefins predominate, as shown in equations $8-10$.

$$
\begin{aligned}
& \mathrm{Ph}_{3} \mathrm{P}=\mathrm{CHEt}+\mathrm{PhCHO} \longrightarrow \bigcup^{\mathrm{Ph}}+\bigodot_{E t}^{\mathrm{Et}} \\
& 85 \% \quad 4 \% \\
& \mathrm{Ph}_{3} \mathrm{P}=\mathrm{CH}-\mathrm{CH}=\mathrm{CH}_{2}+\overbrace{\mathrm{O}}^{\mathrm{CHO}} \\
& \overbrace{0}+\text { cis } \\
& 60 \% \quad 40 \%
\end{aligned}
$$

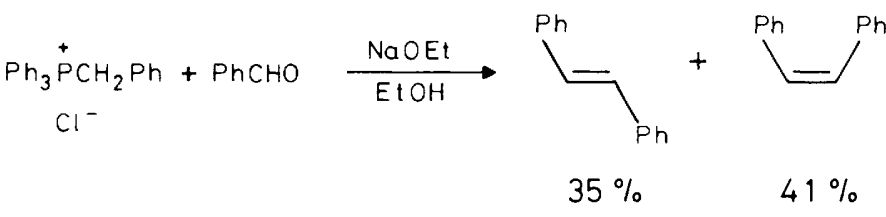

\section{Additions to Carbon-Carbon Double Bonds}

A. Electrophilic Addition of Acids and Halogens.-The Markownikoff addition of electrophiles to carbon-carbon double bonds leads to the regioisomer which may be the slightly more stable one (equation 11 ). However, the regiochemistry of the final products is determined in the first step, in which the most stable possible carbonium ion intermediates are preferentially formed. Therefore, product stability control is ruled out. ${ }^{10}$

$$
\mathrm{RCH}=\mathrm{CH}_{2}+\mathrm{HBr} \longrightarrow{ }_{\mathrm{Br}}^{\mathrm{R}}-\mathrm{C}_{\mathrm{C}}^{\mathrm{H}}-\mathrm{Me}
$$

More interesting is the stereochemistry of electrophilic addition to cyclic olefins. 4-t-Butylcyclohexene adds formic acid to yield mainly the less stable axially-

${ }^{10}$ (a) P. B. D. de la Mare and R. Bolton, 'Electrophilic Additions to Unsaturated Systems', Elsevier, Amsterdam, 2nd Edition, 1982, p. 65; (b) S. Winstein and N. J. Holness, J. Am. Chem. Soc., 1955, 77, 5562; (c) J. Hine, 'Physical Organic Chemistry', McGraw-Hill-Kogakusha, Tokyo, 2nd Edition, 1962, p. 19. 
substituted product (equation 12). ${ }^{10 a, b}$ Addition of hydrogen bromide to 1 cyclohexenecarboxylic acid leads to the less stable $c$ is product (equation 13). ${ }^{11}$ And, addition of bromine to 3-t-butylcyclohexene is presumed to lead initially to the diaxial dibromide in which the cyclohexane ring is in the twist form; this compound then isomerizes to the fully-equatorial compound (equation 14). ${ }^{12} \mathrm{Mechanistically,}$ these reactions presumably take place via the rate-determining formation of bridged intermediates, which suffer axial attack. Thus, the less stable axial isomers are formed initially.
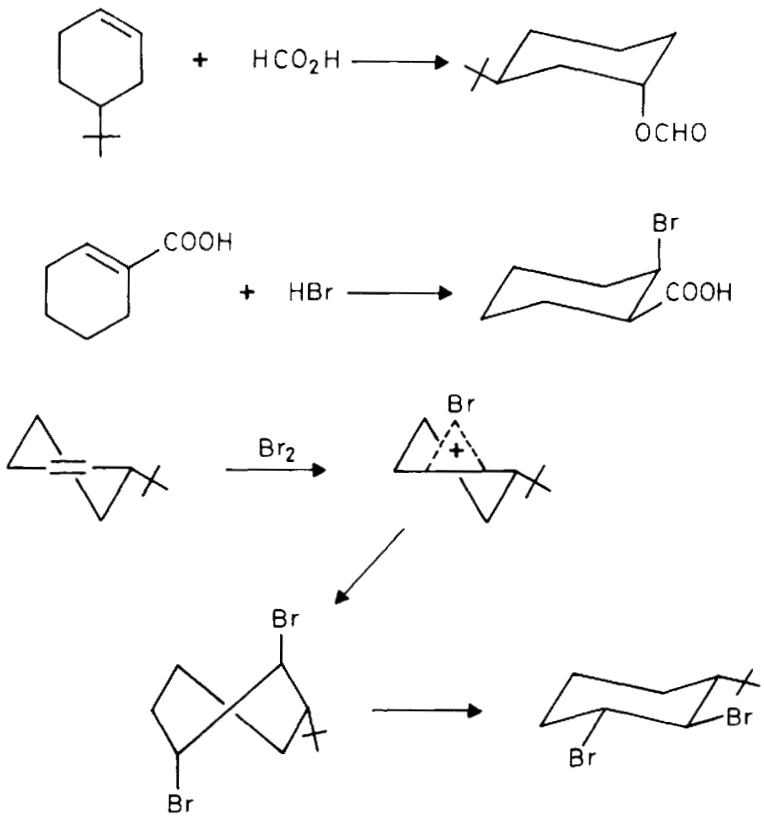

Work in the steroid series also offers interesting examples. 5-Cholestene derivatives add electrophiles to yield products with trans ring junctions (equation 15). ${ }^{13.14}$ However, the nucleophilic parts end-up in axial positions, and that the<smiles>[R]C1CCC2(C)C(=CCC(C)C2C)C1</smiles>

${ }^{11}$ P. B. D. dela Mare and R. Bolton, ref. 10a,p. 363; R.Caple and W. R. Vaughan, Tetrahedron Lett., 1966,4067.

12 P. B. D. de la Mare and R. Bolton, ref. 10a, p. 164; P. L. Barili, G. Bellucci, F. Marioni, I. Morelli, and V. Scartoni, J. Org. Chem., 1972, 37, 4353.

${ }^{13}$ P. B. D. de la Mare and R. Bolton, ref. $10 a$, p. 156.

${ }^{14}$ H. O. House, ref. 1, p. 426; D. H. R. Barton and R. C. Cookson, Chem. Soc. Rev., 1956, 10, 44; D. H. R. Barton and E. Miller, J. Am. Chem. Soc., 1950, 72, 1066. 
products are the less stable isomers is suggested by the rearrangement of similar compounds to $c i s$-fused systems on heating (equation 16). ${ }^{14}$ Finally, it is known that bromine and chlorine add to 2 - and 3-cholestenes preferentially to produce the diaxial dihalides. ${ }^{15}$<smiles>CC1CC=C2C[C@@H](O)CC[C@]2(C)C1C</smiles>

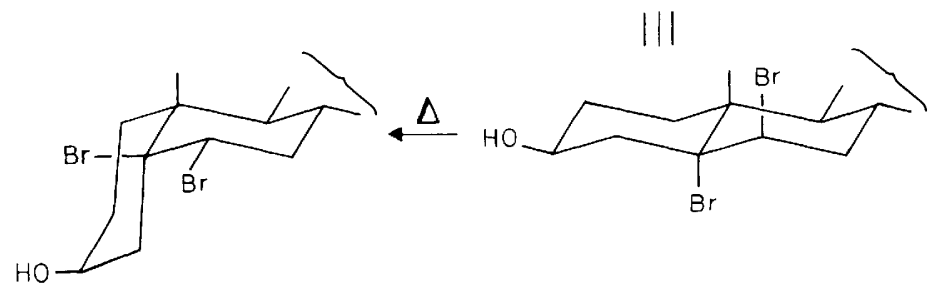

Electrophilic additions to dienes may take place in either 1,2-or 1,4-fashion (equation 17). The less stable 1,2 -addition products are known generally to predominate under kinetic conditions. ${ }^{16}$ For example, in the addition of electrophiles such as $\mathrm{Cl}_{2}, \mathrm{Br}_{2}, \mathrm{ClOAc}$, and $\mathrm{BrOAc}$, the ratio of 1,2- to 1,4-addition ranges from 1.2 to 6.7. 1,4-Addition does, however, lead to the more stable trans isomer; this is probably because the intermediate carbonium ion prefers a transoid geometry. ${ }^{16,17}$

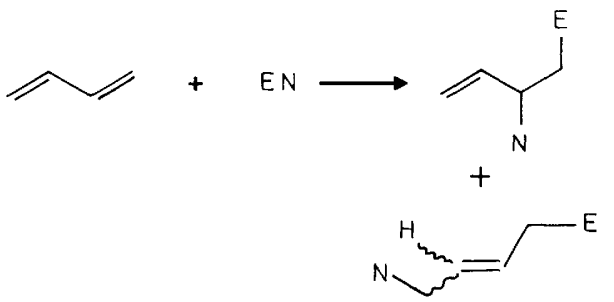

B. Epoxidations.-The epoxidation of an olefin with a peracid usually takes place from the less hindered side of the double bond and the product formed may be the

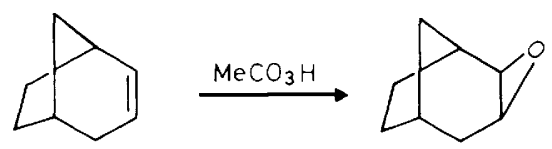

\footnotetext{
15 P. B. D. de la Mare and R. Bolton, ref. 10a, p. 163; G. H. Alt and D. H. R. Barton. J. Chem. Soc., 1954, 4284.

${ }^{16}$ P. B. D. de la Mare and R. Bolton, ref. 10a, pp. 326, 336; V. L. Heasley, G. E. Heasley, R. A. Loghry, and M. R. McConnell, J. Org. Chem., 1972, 37, 2228.

${ }^{17}$ K. Mislow and H. M. Hellmann, J. Am. Chem. Soc., 1951, 73, 244; H. M. Hellmann, J. W. Hellmann, and K. Mislow, ibid., 1954, 76, 1175; K. Mislow, ibid., 1953, 75, 2512.
} 


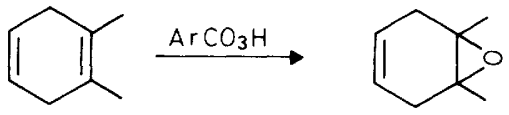

more stable one (equation 18). ${ }^{18}$ However, that product stability is not important in these reactions is suggested by equation 19 , where the more electron-rich double bond is preferentially attacked to yield, probably the less stable product. ${ }^{19}$

Epoxidations of allylic alcohols are dominated by a directing effect of the hydroxyl group. In cyclic systems, this may result in the epoxide ring being cis not only to the hydroxyl group, but also to other groups, which may be as bulky as tbutyl (equation 20). ${ }^{20}$<smiles>CC1CC=CC(O)C1</smiles><smiles>[H][R]([H])([H])[13CH2]C1C(O)CC(C)CC2OC21</smiles>

$96 \%$<smiles>CC(C)(C)C1CC(O)C2OC2C1</smiles>

$4 \%$

C. Hydrogenations. - The catalysed addition of hydrogen to double bonds is known to be insensitive to product stability, the product stereochemistry being mainly determined by the requirement that the addition take place from the less hindered side of the double bond (equations $21-23$ ). ${ }^{21,22}$
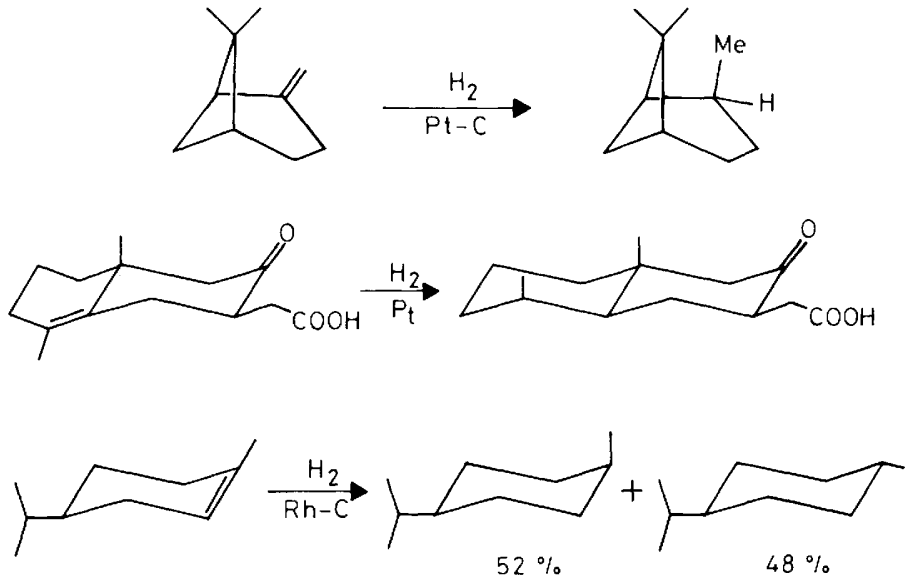

${ }^{18}$ H. O. House, ref. 1, p. 303; R. R. Sauers, H. M. How, and H. Feilich, Tetrahedron, 1965, $21,983$.

19 H. O. House, ref. 1, p. 298; L. A. Paquette and J. H. Barrett, Org. Synth., 1973, Coll. Vol. 5, 467; W. Huckel and U. Worffel, Chem. Ber., 1955, 88, 338.

${ }^{20}$ H. O. House, ref. 1, p. 304; H. B. Henbest, Proc. Chem. Soc., 1963, 159; P. Chamberlain, M. L. Roberts, and G. H. Whitham, J. Chem. Soc. (B), 1970, 1374.

${ }^{21}$ H. O. House, ref. 1, pp. 5, 10, 19; H. C. Brown and C. A. Brown, J. Org. Chem., 1966, 31, 3989; C. A. Brown, J. Am. Chem. Soc., 1969, 91, 5901.

22 J. A. Marshall, N. Cohen, and A. R. Hochstetler, J. Am. Chem. Soc., 1966, 88, 3408. 
D. Hydroboration.-The hydroboration of bicyclic olefins takes place from the less hindered side of the double bond. ${ }^{23}$ Thus, $\alpha$-pinene yields the product shown in equation 24 . The alternative stereoisomer (with the same regiochemistry), which may be of comparable stability, is not formed. Methylenecyclohexanes undergo hydroboration also preferentially to yield the less stable axial products (equation 25 ).
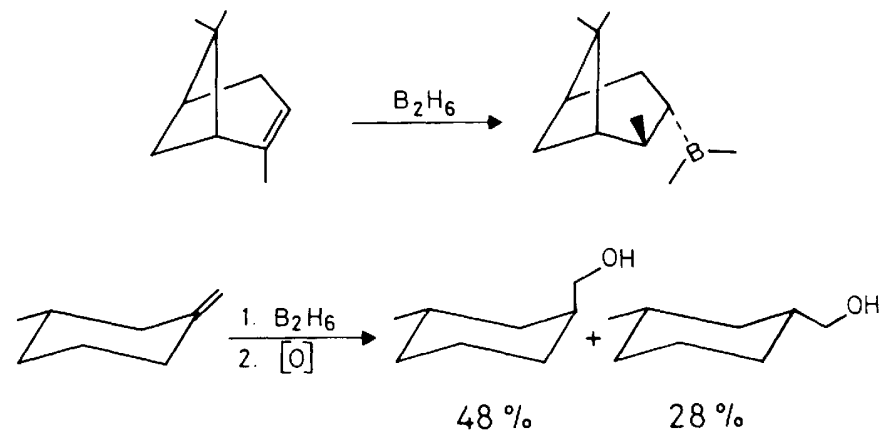

E. Enolate Alkylations.--Kinetically-controlled alkylations of ketone enolates can yield the less stable products (equations 26-29). ${ }^{24}$ The stereochemistry of alkylation is thought to be mainly determined by the ease of approach of the alkylating agent to the intermediate enolate ion, as also by stereoelectronic factors, rather than by product stability. ${ }^{25}$<smiles>CC1=C[C@H]2CCCC[C@]2(C)CC1</smiles>

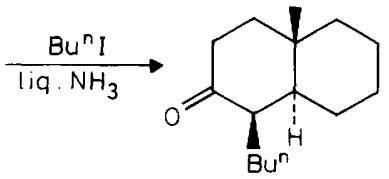<smiles>COC1=C(CCC=C(C)C)C2CCC1C2</smiles>

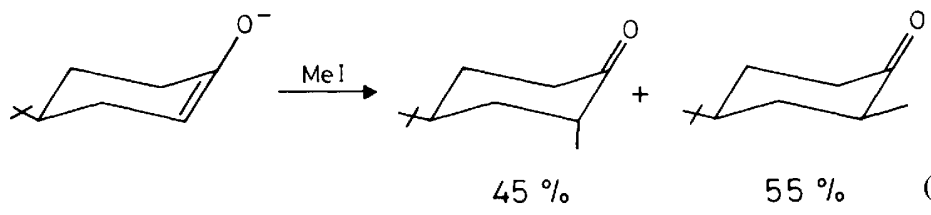

${ }^{23}$ H. O. House, ref. 1, p. 110; H. C. Brown and G. Zweifel, J. Am. Chem. Soc., 1961, 83, 2544; ibid., 1964, 86, 393; J. Klein and D. Lichtenberg, J. Org. Chem., 1970, 35, 2654.

${ }^{24}$ H. O. House, ref. 1, p. 587.

${ }^{25}$ E. J. Corey, R. Hartmann, and P. A. Vatakencherry, J. Am. Chem. Soc., 1962, 84, 2611; H. O. House and B. M. Trost, J. Org. Chem., 1965, 30, 1341, 2502; B. J. L. Huff, F. N. Tuller, and D. Caine, J. Org. Chem., $1969,34,3070$. 


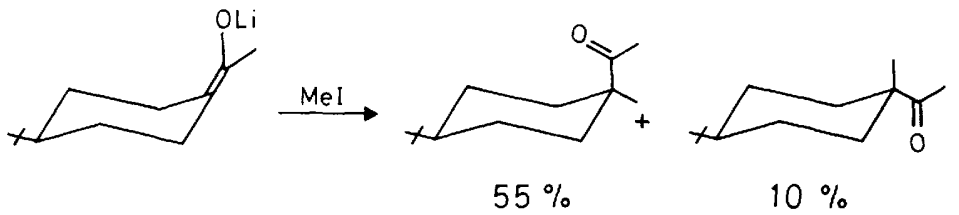

Likewise, alkylations of acyclic enolates are known preferentially to yield the (presumably) less stable erythro products. ${ }^{26 a}$ And, enamines of cyclic ketones, on alkylation, preferentially yield axially-substituted products. ${ }^{26 b}$

F. Conjugate Additions--1,4-Addition of organocopper derivatives to conjugated enones has been well-studied. Stereoelectronic factors appear to control the reaction and the products obtained may be the less stable ones (equations 30 and 31). ${ }^{27}$ (It must be mentioned that some $c i s$-decalin derivatives are actually more stable than their trans isomers. ${ }^{28 a}$ Therefore, equation 30 may not rule out productstability control; equation 31 , however, does!).<smiles>[R]C1=C2C[C@@H](C(=C)C)CC[C@]2([R])CCC1=O</smiles><smiles>C[C@H]1CC12CC(=O)C2</smiles>

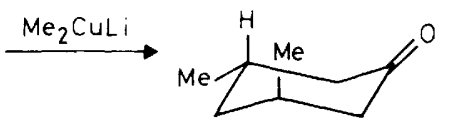

\section{$98 \%$}

Similarly, Michael additions show insensitivity to product stability; the course of the reaction is determined by the requirement that the addition take place from the less hindered side of the conjugated system. ${ }^{28 b}$

\section{Pericyclic Reactions}

Regio- and stereoselectivity in various pericyclic reactions are under orbital symmetry control. Hence, product stability is not important, although there are examples in which the more stable products predominate.

${ }^{26}$ (a) W. G. Kenyon, R. B. Meyer, and C. R. Hauser, J. Org. Chem., 1963, 28, 3108; (b) S. Karady, M. Lenfant, and R. E. Wolff, Bull. Soc. Chim. Fr., 1965, 2472.

27 P. Deslongchamps, 'Stereoelectronic Effects in Organic Chemistry', Pergamon Press, Oxford, 1983, p. 221; G. H. Posner, Org. React. (N.Y.), 1972, 19, 19; E. Piers and R. J. Keziere, Tetrahedron Lett., 1968, 583; J. A. Marshall and H. Roebke, J. Org. Chem., 1968, 33, 840; J. A. Marshall, W. I. Fanta, and H. Roebke, ibid., 1966, 31, 1016; S. M. McElvain and D. C. Remy, J. Am. Chem. Soc., 1960, 82, 3960; H. O. House and W. F. Fischer, Jr., J. Org. Chem., 1968, 33, 949.

${ }^{28}$ (a) E. L. Eliel, ref. 7, p. 279 ; (b) H. O. House, ref. 1, p. 615. 
Familiar examples are the Diels-Alder reactions of cyclopentadiene, which preferentially yield the less stable endo products (equation 32). ${ }^{29}$ The accepted explanation for this phenomenon is that secondary orbital interactions stabilize the transition state leading to the endo product.

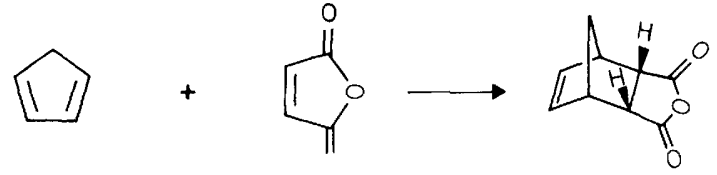

Regioselectivity in these reactions is also independent of product stability as shown by the preferred formation of the less stable 'ortho' adducts (equations 33 and 34$).{ }^{30,31}$ Such regioselectivity is supposedly due to the preferred overlapping of orbitals of similar size in the transition state.

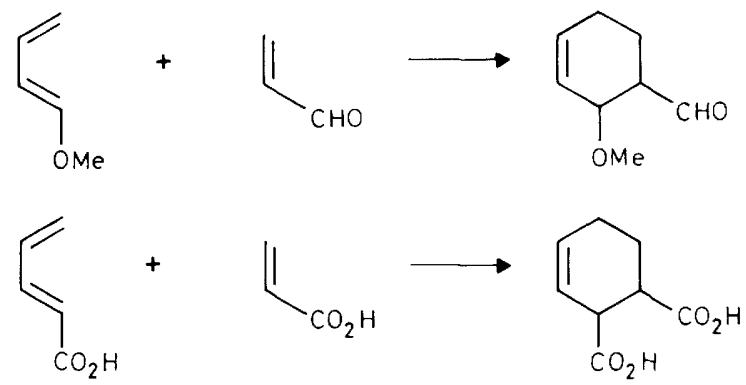

Electrocyclic reactions, too, ignore product stability. For example, the disrotatory cyclization of the octatriene in equation 35 yields the 1,3-cyclohexadiene with the methyl groups mutually disposed in the less stable cis fashion. ${ }^{32}$

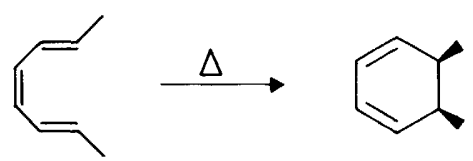

\section{Elimination Reactions}

Eliminations leading to olefins are mainly of three types, $E 1, E 1 \mathrm{cB}$ and $E 2$. Both the regio- and stereochemistry of the product olefins are important in determining

${ }^{29}$ I. Fleming, 'Frontier Orbitals and Organic Chemical Reactions', Wiley, London, 1976, p. 106; R. Hoffmann and R. B. Woodward, J. Am. Chem. Soc., 1965, 87, 4388.

30 I. Fleming, ref. 29, p. 121; O. Wichterle, Collect. Czech. Chem. Commun., 1938, 10, 497.

31 I. Fleming, ref. 29, p. 129; K. Alder, M. Schumacher, and O. Wolff, Annalen, 1949, 564, 79; K. Alder and K. Heimbach, Chem. Ber., 1953, 86, 1312.

32 I. Fleming, ref. 29, p. 105; E. Vogel, W. Grimme, and E. Dinné, Tetrahedron Lett., 1965, 391; E. N. Marvel, G. Caple, and B. Schatz, ibid., 1965, 385. 
stabilities, the more highly substituted, and the trans, isomers being generally more stable.

A. E1 Reactions.- These reactions take place via the rate-determining formation of carbonium ions, followed by loss of protons, to yield olefins (equation 36). When $R$ is a primary or a secondary alkyl group, the more substituted olefin predominates (Saytzeff product). When $R$ is a tertiary alkyl group, the less substituted olefin, which however is the more stable isomer, predominates. It has been stated as a general rule that, in an $E 1$ reaction, the most stable possible olefin is formed via the most stable possible carbonium ion. ${ }^{33}$

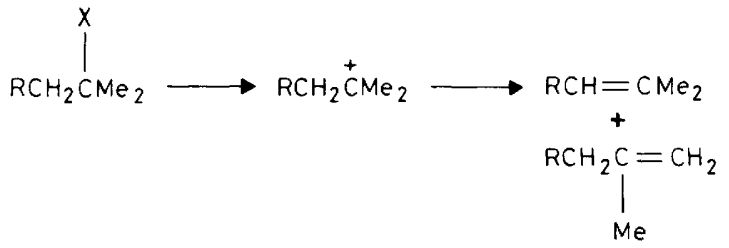

The simplest explanation for Saytzeff elimination is product-stability control. This also appears to be generally accepted by workers in this area. ${ }^{33,34}$

B. $\boldsymbol{E} 2$ Reactions. - The regio- and stereochemistry of the products in bimolecular elimination reactions, involving both the substrate and a base in the transition state, vary widely.

Both steric and electronic factors are thought to be important in determining regiochemistry in $E 2$ reactions. In the absence of steric effects, Saytzeff orientation, leading to the more stable olefin obtains. However, when steric factors are important, as when the leaving group or the attacking base is bulky, Hofmann orientation leading to the less stable olefin obtains.

As an example, consider the dehydrobromination reaction in equation $37 .{ }^{35,36}$ When the attacking base is the ethoxide ion, the more substituted olefin predominates $(81 \%)$. However, when the base is the t-butoxide ion, the terminal olefin is also obtained $(53 \%)$. The effect of a bulky leaving group is shown in equation $38 .^{35 a .36}$

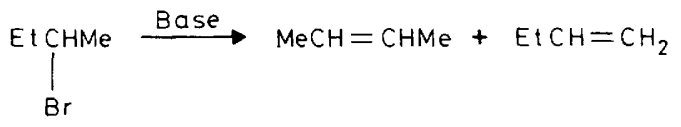

${ }^{33}$ (a) W. H. Saunders, Jr. and A. F. Cockerill, 'Mechanisms of Elimination Reactions', Wiley, New York, 1973, p. 212; (b) H. C. Brown and M. Nakagawa, J. Am. Chem. Soc., 1955, 77, 3610.

${ }^{34}$ D. V. Banthorpe, 'Elimination Reactions', Elsevier, Amsterdam, 1963, p. 59.

${ }^{35}$ (a) W. H. Saunders, Jr. and A. F. Cockerill, ref. 33, p. 165; (b) M. L. Dhar, E. D. Hughes, and C. K. Ingold, J. Chem. Soc., 1948, 2058.

${ }^{36}$ E. D. Hughes, C. K. Ingold, G. A. Maw, and L. I. Woolf, J. Chem. Soc., 1948, 2077. 


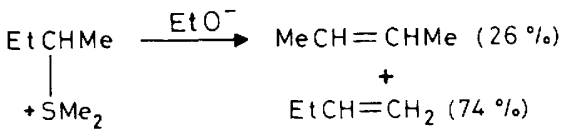

The reason for these phenomena is supposed to be that, in the absence of steric effects, these reactions are under product-stability control. When steric effects become important, the attacking base deprotonates the least hindered proton to yield the less substituted olefin.

The stereochemistry of elimination is also interesting. Generally, the more stable trans olefins predominate, as in equation 39 , and product-stability control has been invoked as an explanation. ${ }^{35 a, 37}$

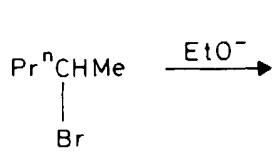

$\mathrm{Br}$

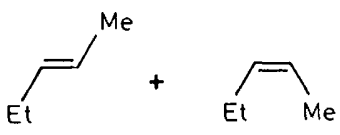

$51 \%$

$18 \%$

$31 \%$

Other theories have also been proposed to explain the predominance of the more stable olefin in $E 2$ reactions. McLennan has pointed out that the yield of more stable olefin is sometimes much greater than is warranted by its stability. ${ }^{38}$ Thus, the above author has proposed an alternative explanation to product-stability control. According to this theory, applicable to eliminations induced by weak bases on loose substrates, ground-state steric interactions in the substrate are important. Such interactions, between the substituents on the more substituted $\beta$-carbon and the other $\beta^{\prime}$-alkyl group, will be better relieved on going to the more substituted olefin (Figure 2).

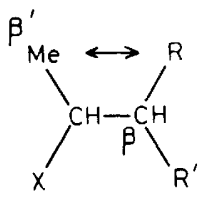

Figure 2

Steric interactions between the attacking base and the groups $(R)$ on the $\beta$ carbon atom are also supposed to destabilize the transition state leading to the less substituted olefin.

${ }^{37}$ H. C. Brown and O. H. Wheeler, J. Am. Chem. Soc., 1956, 78, 2199.

${ }^{38}$ D. J. McLennan, Tetrahedron, 1975, 31, 2999. 
Another important point is that, in $E 2$ reactions, the requirement that the leaving group and the hydrogen being removed be antiperiplanar, usually overrides considerations of product stability. ${ }^{39}$

C. Cyclic Eliminations.-The decomposition of acetates, xanthates, and amine oxides is an important preparative method for olefins; interesting orientation results are found. ${ }^{40}$

These reactions are all cis-eliminations. Generally, factors other than product stability are thought to be important. In acyclic systems a statistical factor determined by the number of $\beta$-hydrogens is supposed to dominate (equation 40). ${ }^{41}$ However, when an aryl substituent is present, stability is probably important (equation 41$)^{42}$<smiles>CCC(C)=[C+]C(C)=CC#CC(C)(C)OC(C)(C)CC</smiles>

$$
76 \%
$$

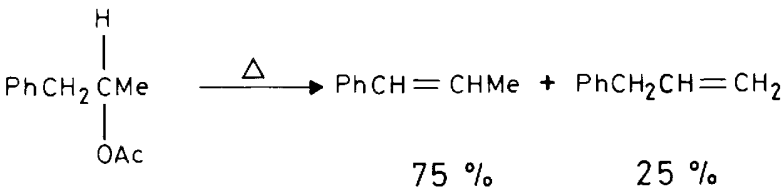

In cyclic systems, an axial-equatorial alignment of the eliminating groups is favoured over an equatorial-equatorial alignment. This appears to be the main factor determining product composition (equation 42 ). ${ }^{43}$

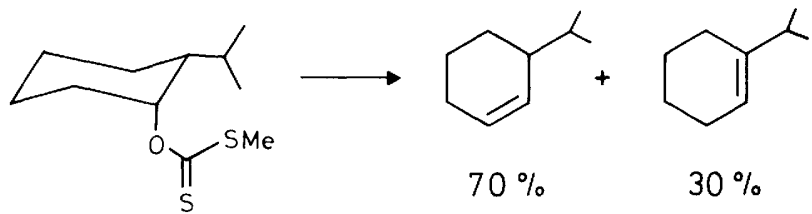

However, in acetate and xanthate pyrolyses, the more stable endo olefins are

${ }^{39}$ W. H. Saunders, Jr. and A. F. Cockerill, ref. 33, p. 116; E. D. Hughes, C. K. Ingold, and J. B. Rose, J. Chem. Soc., 1953, 3839; E. D. Hughes and J. Wilby, ibid., 1960, 4094; W. Hueckel, W. Tappe, and G. Legutke, Annalen, 1940, 543, 191.

40 W. H. Saunders, Jr. and A. F. Cockerill, ref. 33, pp. 409, 427, 447.

${ }^{41}$ D. H. Fremsdorf, C. H. Collins, G. S. Hammond, and C. H. DePuy, J. Am. Chem. Soc., 1959, 81, 643; W. O. Haag and H. Pines, J. Org. Chem., 1959, 24, 877.

42 W. J. Bailey and C. King, J. Org. Chem., 1956, 21, 858.

${ }^{43}$ F. G. Bordwell and P. S. Landis, J. Am. Chem. Soc., 1958, 80, 6379; W. Hueckel, W. Tappe, and G. Legutke, Annalen, 1940, 543, 191; R. T. Arnold, G. G. Smith, and R. M. Dodson, J. Org. Chem., 1950, 15, 1256; W. J. Bailey and L. Nicholas, J. Org. Chem., 1956, 21, 854. 
predominantly formed (equation 43 ) ${ }^{44}$ Product-stability control seems the most likely explanation, although it has been suggested that entropic factors favour the formation of endo olefins. This is because there is a loss of freedom of rotation of the methyl groups in the transition state leading to exo olefin. ${ }^{45}$

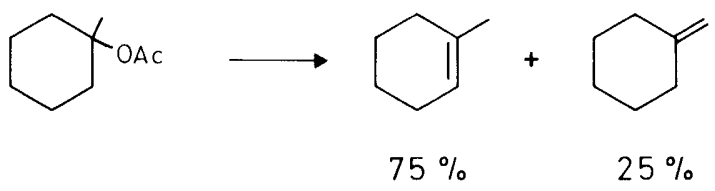

In contrast, the corresponding Cope elimination yields almost exclusively the exo olefin (equation 44). ${ }^{46}$ It is thought that this is because, in the transition state for the formation of the endo olefin, the cyclohexane ring would have to adopt the less stable boat conformation, whereas the exo olefin can be formed via the chair transition state.

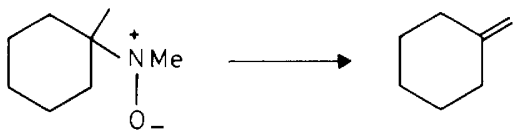

Finally, the Cope eliminations in equations 45 and 46 may be mentioned.$^{47}$ In the trans isomer (equation 46), axial-equatorial elimination can lead to either orientation of the double bond. Whether the predominance of the conjugated

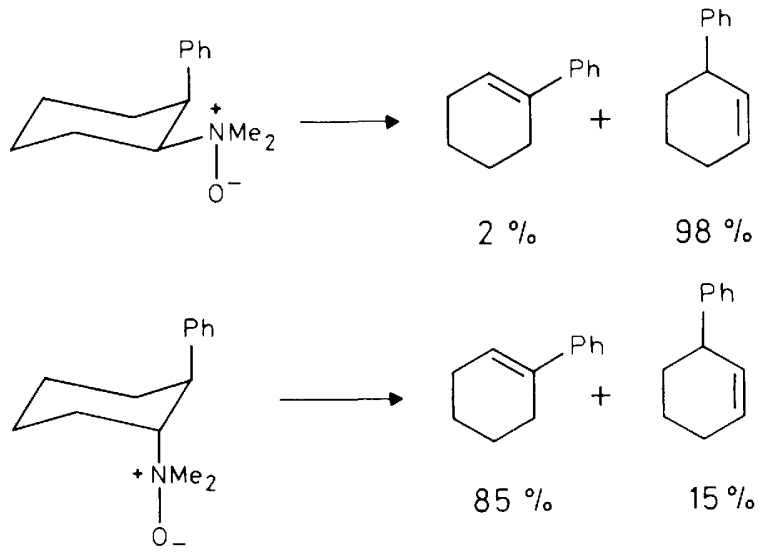

${ }^{44}$ W. J. Bailey and W. F. Hale, J. Am. Chem. Soc., 1959, 81, 647, 651.

45 D. V. Banthorpe, ref. 34 , p. 175.

46 A. C. Cope, C. L. Bumgardner, and E. E. Schweizer, J. Am. Chem. Soc., 1957, 79, 4729.

47 A. C. Cope and C. L. Bumgardner, J. Am. Chem. Soc., 1957, 79, 960. 
isomer is due to its greater stability or to the greater acidity of the $\mathrm{PhC}-\mathrm{H}$ hydrogen in the reactant is not clear.

\section{Cyclization Reactions}

Much is known about the thermodynamic and kinetic factors affecting cyclization reactions. Amongst the small and medium rings, six-membered rings are the most stable, followed by five-membered rings. However, five-membered rings are generally formed the fastest, followed by six-membered rings.

Thus, the equilibrium constant for the cyclization reaction in equation 47 is about 16 , whereas it is about 8 for the analogous reaction leading to a fivemembered ring. The equilibrium constants for the corresponding reactions forming three- and four-membered rings are negligible, and for the reactions forming sevenand eight-membered rings, are said to be 0.2 and 0.1 respectively. ${ }^{48}$

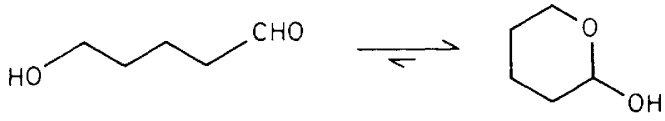

It is interesting to compare these trends with the relative rates of formation of rings of various sizes. ${ }^{48}$ For the reaction in equation 48 , the relative rates for various values of $n$ are as follows:

$$
\begin{array}{lccccccc}
n & 3 & 4 & 5 & 6 & 7 & 10 & 15 \\
k_{\text {relative }} & 3.12 & 0.002 & 100 & 1.7 & 0.03 & 10^{-8} & 10^{-4} \\
\mathrm{H}_{2} \mathrm{~N}\left(\mathrm{CH}_{2}\right)_{n-2} & & & & & & & \\
\mathrm{CH}_{2} \mathrm{Br} & \longrightarrow & & & \left(\mathrm{CH}_{2}\right)_{n-2}
\end{array}
$$

The most striking feature is that the five-membered ring is formed faster than the more stable six-membered ring. Similarly, the three-membered ring is formed faster than the more stable four-membered ring; this is thought to be due to an entropy effect, the ends of a chain of three atoms being closer together than those of a chain of four. However, the dramatic rise in the value of $k$ on going from $n=4$ to $n=5$, may well be due to product-stability control. The strain energies for the 3-, 4-, 5-, and 6-membered cycloalkanes are 9.2,6.6,1.3, and $0.0 \mathrm{kcal} \mathrm{mol}^{-1}$ respectively. ${ }^{49}$ Thus, the difference in strain energies between the four- and five-membered rings is about twice that between the three- and four-membered rings, which may explain the importance of product stability in the formation of the five-membered ring. In other words, in the formation of five-membered rings, a balance is achieved between the product-stability and entropic factors.

${ }^{48}$ R. O. C. Norman, 'Principles of Organic Synthesis', Chapman and Hall, London, 2nd Edition, 1978, pp. 23, 90; P. R. Jones, Chem. Rev., 1963, 63, 470; C. D. Hurd and W. H. Saunders, Jr., J. Am. Chem. Soc., 1952, 74, 5324; A. A. Frost and R. G. Pearson, 'Kinetics and Mechanism', Wiley, New York, 2nd Edition, 1961, p. 297; G. Salomon, Helv. Chim. Acta, 1933, 16, 1361.

49 J. March, 'Advanced Organic Chemistry', McGraw-Hill-Kogakusha, Tokyo, 2nd Edition, 1977, p. 145; E. L. Eliel, ref. 7, p. 189. 
<smiles>[Y]C1CCC([Y])C1</smiles>

Favoured<smiles>[Y]1CCNCC1</smiles>

\section{Disfavoured}<smiles>c1ccccc1</smiles>

Scheme 2

Baldwin's 'Rules for Ring Closure' also highlight the unimportance of product stability in cyclization reactions. ${ }^{50}$ Preferred modes of cyclization are determined by the structural features of the reactants, rather than by product stability. For example, 5- and 6-endo-tet reactions are disfavoured, whereas 3- and 4-exo-tet closures, leading to strained three- and four-membered rings respectively, are favoured (Scheme 2). However, closures leading to five- and six-membered rings in the exo-tet mode are favoured.

Similarly, 3- to 5-endo-trig closures are disfavoured whereas 3- to 7-exo-trig closures are favoured. Again, 3- to 4-exo-dig processes are disfavoured, whereas 3- to 7-endo-dig processes are favoured. These illustrate, in a way, that the stability of a ring is not very important to its rate of formation. Dramatic examples of the formation of the less stable products, in accord with these rules, are shown in equations 49 and 50.
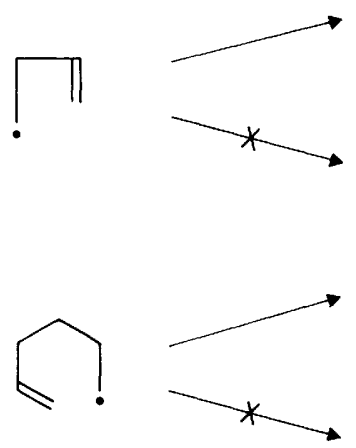
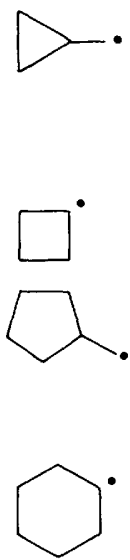

so J. E. Baldwin, J. Chem. Soc., Chem. Commun., 1976, 734. 


\section{Aromatic Electrophilic Substitutions}

Kinetic and thermodynamic products may be different in aromatic electrophilic substitution reactions. For example, sulphonation of naphthalene under kinetic conditions $\left(80^{\circ} \mathrm{C}\right)$ yields 1 -naphthalenesulphonic acid, whereas the thermodynamically-controlled product is 2-naphthalenesulphonic acid (equation 51). Similarly, kinetically-controlled methylation of toluene yields only $o$ - and $p$-xylene, whereas the equilibrium composition is $60 \% \mathrm{~m}$-, 20\%o-, and $20 \% \mathrm{p}$-xylene (equation 52). ${ }^{51}$ Mechanistically, these reactions take place via the ratedetermining formation of $\sigma$-complex intermediates.

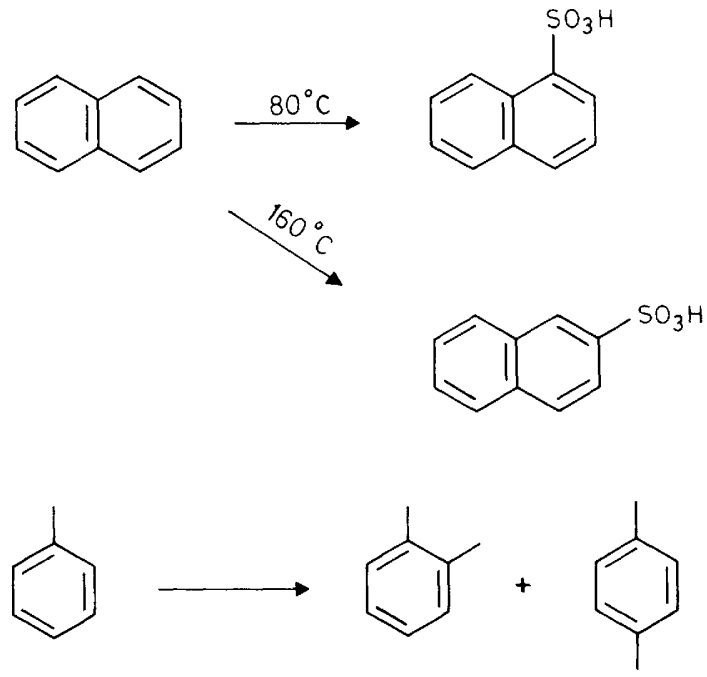

\section{Other Reactions}

A. Dissolving Metal Reductions.-A variety of functional groups is reduced by dissolving metals. However, only the reduction of conjugated systems is interesting in the context of this review. (Although the reduction of cyclic ketones is known to give the more stable alcohol products, a consideration of the mechanism shows that these reactions are not kinetically controlled. ${ }^{52}$ )

The Birch reduction of various aromatic systems is known to yield the less stable unconjugated dienes (equations 53-55). ${ }^{53-55}$ The reason adduced for this

51 J. Hine, 'Physical Organic Chemistry', McGraw-Hill-Kogakusha, Tokyo, 2nd Edition, 1962, p. 380.

${ }^{52}$ H. O. House, ref. 1, p. 150; J. F. Huffmann and J. T. Charles, J. Am. Chem. Soc., 1968, 90, 6486; A. Coulombeau and A. Rassat, J. Chem. Soc., Chem. Commun., 1968, 1587.

${ }^{53}$ (a) H. O. House, ref. 1, p. 188; (b) N. L. Bauld, J. Am. Chem. Soc., 1962, 84, 4347; D. R. Weyenberg, L. H. Toporcer, and L. E. Nelson, J. Org. Chem., 1968, 33, 1975.

54 A. P. Krapcho and A. A. Bothner-By, J. Am. Chem. Soc., 1959, 81, 3658; ibid., 1960; 82, 751.

55 K. C. Bass, Org. Synth., 1962, 42, 48; F. Camps, J. Coll, and J. Pascual, J. Org. Chem., 1967, 32, $2563 ;$ A. L. Wilds and N. A. Nelson, J. Am. Chem. Soc., 1953, 75, 5360, 5366. 

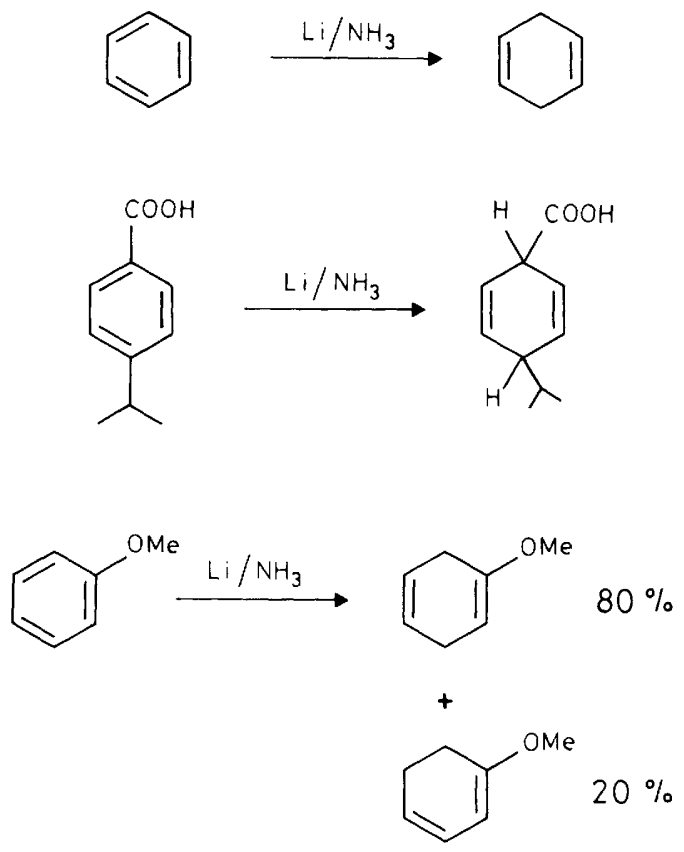

phenomenon is that, in the highest-occupied molecular orbital of the intermediate anion, electron density is greatest at the middle carbon of the pentadienyl system. Protonation, which is fastest at this site, then leads to the unconjugated product.

Similar reactions include electrophilic attack at the middle carbon of the pentadienyl anion, and the deconjugation of $\alpha, \beta$-unsaturated ketones. ${ }^{56-57}$

Finally, the reduction of 1,3-butadiene is reported to yield 2-butene (equation 56). ${ }^{53 b}$ However, in the light of the above discussion, product-stability control is probably unlikely.

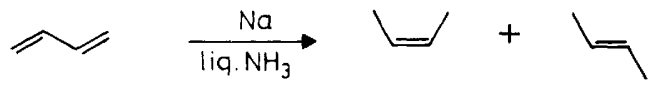

B. Epoxide Cleavages.-The cleavage of a cyclohexene oxide takes place in such a way as to place the resulting substituents in the trans-diaxial rather than in the trans-diequatorial positions (equation 57). ${ }^{58}$

56 I. Fleming, ref. 29 , p. 45.

${ }^{57}$ H. O. House, ref. 1, p. 502; H. J. Ringold and S. K. Malhotra, Tetrahedron Lett., 1962, 669; J. Am. Chem. Soc., 1962, 84, 3402; S. K. Malhotra and H. J. Ringold, J. Am. Chem. Soc., 1963, 85, 1538; ibid., 1964; 86, 1997; ibid., 1965, 87, 3228.

${ }^{58}$ H. O. House, ref. 1, p. 301; H. B. Henbest, M. Smith, and A. Thomas, J. Chem. Soc., 1958, 3293; G. H. Alt and D. H. R. Barton, ibid., 1954, 4284; J. Gorzynski Smith, Synthesis, 1984, 629. 


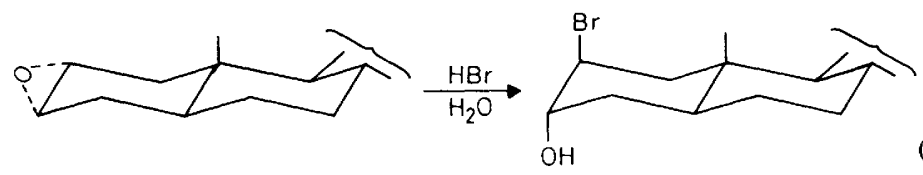

The opening of epoxides by organometallic reagents has been well-studied. The regiochemistry of the products is determined by the fact that attack is at the less hindered position (equation 58). ${ }^{59}$

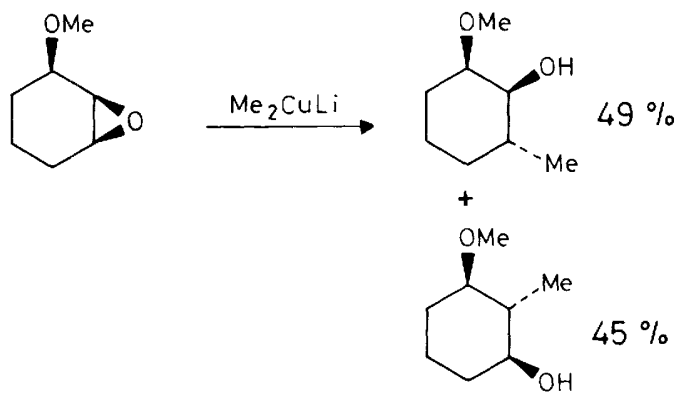

Apparently, there is no evidence for product-stability control in these reactions.

C. Photochemical Reactions.-The Paterno-Büchi reaction often yields, probably the less stable, products (equation 59); so does olefin dimerization (equation 60). ${ }^{60}$ The reason for the observed orientations is that the reactions are under frontierorbital control; therefore, product stability is unimportant.
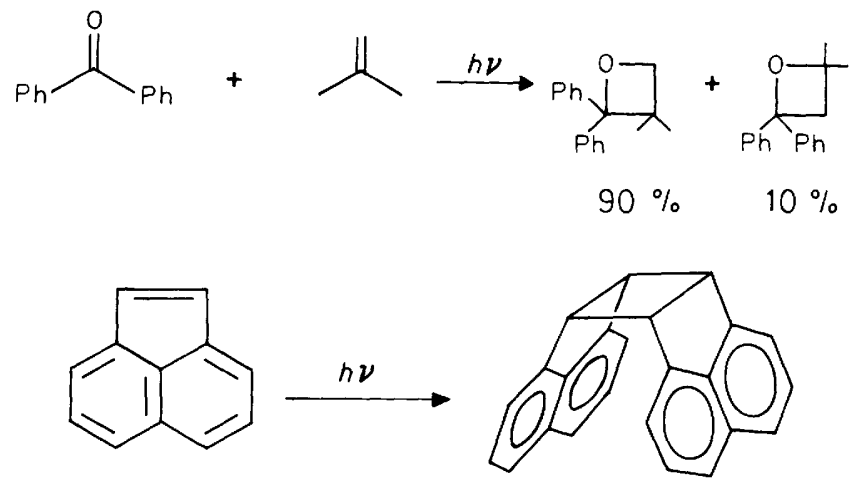

D. Miscellaneous.--In the Baeyer-Villiger oxidation, the course of the reaction is

${ }^{59}$ G. H. Posner, Org. React. (N.Y.), 1975, 22, 287; B. C. Hartmann, T. Livinghouse, and B. Rickborn, J. Org. Chem., 1973, 38, 4346.

${ }^{60}$ I. Fleming, ref. 29, p. 213; D. R. Arnold, R. L. Hinman, and A. H. Glick, Tetrahedron Lett., 1964, 1425; D. O. Cowan and R. L. E. Drisko, J. Am. Chem. Soc., 1970, 92, 6286. 
determined solely by the nature of the group migrating to electron-deficient oxygen. The less stable product may be formed preferentially (equation 61 ) ${ }^{61}$<smiles>CC(=O)c1ccccc1</smiles>

The $S_{N} 1^{\prime}$ reaction of many allylic halides can lead to the predominant formation of the less stable products (equation 62 ). ${ }^{62}$

$$
\begin{aligned}
\mathrm{Me}_{2} \mathrm{C}=\mathrm{CHCH}_{2} \mathrm{Cl} \stackrel{\mathrm{H}_{2} \mathrm{O} \longrightarrow \mathrm{Me}_{2} \mathrm{C}}{\mathrm{C}}-\mathrm{CH}=\mathrm{CH}_{2} \\
+ \\
+85 \% \\
\mathrm{Me}_{2} \mathrm{C}=\mathrm{CHCH}_{2} \mathrm{OH} \\
15 \%
\end{aligned}
$$

Allylic halogenation is known to give a predominance of the more stable product. However, this is because of equilibration of the product mixture under the reaction conditions. ${ }^{63}$

\section{Summary of Survey of Reactions}

A variety of organic reaction classes has now been surveyed to ascertain the importance of product stability in determining product composition. The selection of reactions has been representative rather than exhaustive. Examples which are clear-cut or which are of synthetic importance have been chosen. Some of the reactions surveyed, such as additions to carbon-oxygen multiple bonds, additions to carbon-carbon multiple bonds, and elimination reactions, have been subjected to rigorous mechanistic study by various workers. The following general conclusions may be drawn from the survey:

(1) There are a large number of reactions in which the less stable products are formed faster. Thus, kinetic and thermodynamic products are different for most organic reactions. Unambiguous examples of product stability determining product composition are rare. In other words, again, product-stability control is the exception rather than the rule. Further, even when the more stable product is

\footnotetext{
${ }^{61}$ H. O. House, ref. 1, p. 321; R. R. Sauers and R. W. Ubersax, J. Org. Chem., 1965, 30, 3939; C. H. Hassall, Org. React. (N.Y.), 1957, 9, 73.

62 J. March, 'Advanced Organic Chemistry', McGraw-Hill-Kogakusha, Tokyo, 2nd Edition, 1977, p. 307; R. H. de Wolfe and W. G. Young, Chem. Rev., 1956, 56, 753.

${ }^{63}$ H. O. House, ref. 1, p. 485; L. Bateman and J. I. Cuneen, J. Chem. Soc., 1950, 941.
} 
formed faster, factors other than product stability have been proposed as explanations. And, sometimes, the proportion of the more stable product is greater than warranted by its stability.

(2) Elimination reactions provide a few examples of apparent product-stability control. This is especially true of $E 1$ reactions. Some cyclization reactions could also be under product-stability control.

(3) In some reactions, such as electrophilic additions to olefins and epoxide cleavages, the less stable products are apparently the only possible ones, given the mechanisms of the reactions. However, it is interesting that the reactions do not change mechanism to avoid formation of the less stable products.

(4) When a reaction takes place via intermediates, the final product-forming step is rarely rate determining. The rate-determining step usually occurs early along the reaction co-ordinate.

\section{Possible Explanations}

These intriguing findings pose a challenge to present theories of chemical reactivity, such as transition state theory. By definition, the transition state lies in-between reactants and products. Why then is product stability unimportant? The following qualitative explanations are possible and they can be classified into two general categories:

\section{A. Explanations Involving the Position of the Transition State along the Reaction Co-} ordinate. - The reduction of ketones with complex metal hydrides is a reaction which serves as a convenient starting point for the discussion. This reaction class, in addition to having attracted attention to the above phenomenon, is also the most thoroughly studied. ${ }^{1-6}$ The accepted explanation appears to be that such reductions take place via early, reactant-like, transition states. Hence, product stability is thought to be unimportant.

The reasons for this are not very clear. One possible reason is that, the reactions being exothermic, the Hammond postulate is applicable. According to this postulate, in exothermic reactions the transition states resemble the reactants in geometry, as these species are closer together along the reaction co-ordinate. ${ }^{64}$ Although the postulate was actually meant to be applied to reactive intermediates, whose reactions are highly exothermic, it can probably be extended to less exothermic reactions. ${ }^{6}$ (Two reaction classes to which the Hammond postulate is certainly applicable are electrophilic additions to olefins, and dissolving metal reductions. These reactions take place via carbocations and carbanions, respectively; the transition states for the formation of products are expected to resemble the intermediates rather than the products.)

Interestingly, most organic reactions are exothermic. Or rather, organic

${ }^{64}$ J. March, ref. 62, p. 194; G. S. Hammond, J. Am. Chem. Soc., 1955, 77, 334. 
reactions are studied and used mostly in the exothermic directions. Endothermic reactions need to be driven to completion (by removal of a product) and are, therefore, less convenient to perform.

It is also noteworthy that saturated systems are generally of lower energy than unsaturated systems. Therefore, in additions to unsaturated systems the transition states would be expected to be reactant-like, as such reactions are generally exothermic. Hence, product stability would be unimportant. However, reactions in which the products are 'more unsaturated' than the reactants, are expected to be endothermic and the transition states to possess some product character; product stability would then be important.

Table

Isomers
(Possible Products)

(1)
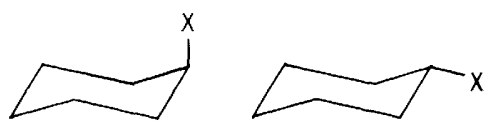
$\mathrm{x}=\mathrm{OH}$
$0.4-0.9$
$x=$ halogen
$0.25-0.70$
$x=\mathrm{COOH}$

(2)<smiles>COC(=O)C1CC2C=CC1C2</smiles><smiles>C1CCCC1</smiles>

(3)
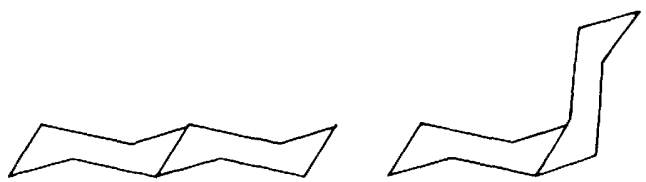

2.4

(4)

$$
\begin{gathered}
\left.\mathrm{Ph} \underset{\mathrm{Br}}{\mathrm{CH}}\right|_{(\text {meso }} ^{\mathrm{CH}} \\
\mid
\end{gathered}
$$

(5)

$$
\text { xylene }
$$

$$
(m-) \quad(o-+p-) \quad<0.4
$$


Table (contd)

\title{
Isomers
}

(Possible Products)

\author{
$|\Delta E|$ (kcals/mole)
}

(6)<smiles>CC1=CCCCC1</smiles><smiles>C=C1CCCCC1</smiles>

(7)<smiles>C=CCC</smiles><smiles>CC=CC</smiles>

2.5

(8)<smiles>C=CC(C)C</smiles><smiles>CC=C(C)C</smiles>

3. 2

(9)

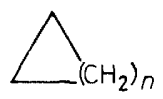
$(n=1)$
$(n=2)$
2. 6
$(n=2)$
$(n=3)$
5. 3
$(n=3)$
$(n=4)$
1. 3

The fact that elimination reactions are generally endothermic agrees with the above arguments. For, these reactions, as a class, offer the largest number of examples of product-stability control.

An alternative explanation, not explicitly involving the Hammond postulate, is as follows. The energy of a transition state is assumed to be mainly that of steric repulsion between the colliding reactant molecules. As bonding progresses, the repulsive interactions are gradually offset. Now, bonding interactions are expected to offset repulsive interactions better in exothermic than in endothermic reactions. This is because bonding interactions release more energy in exothermic reactions. The result is that the energy maximum, i.e. the transition state, occurs earlier along the reaction co-ordinate for exothermic reactions. Therefore, the transition state would be expected to be reactant-like, for exothermic reactions.

To sum up, then, organic reactions generally involve additions to multiple bonds and are, therefore, exothermic. The transition states for exothermic reactions resemble the reactants rather than the products. Hence product stability is unimportant. 
B. Explanations Not Involving the Position of the Transition State along the Reaction Co-ordinate.--Insensitivity to product stability may be due either to the transition state not possessing enough product character, or to the differences in product stability being small. The first of these possibilities was discussed above. The second is now considered below.

For differences in transition-state energies to be derived from the differences in product stabilities, the latter energy differences would have to be at least equal to the former. Interestingly, such a relationship is rather rare. Differences in stability of possible products (say, related isomers) are considerable only for olefins. For saturated systems, such energy differences are generally much smaller (less than about $2 \mathrm{kcal} \mathrm{mol}^{-1}$ ), as seen in the table on pp. 336-337. ${ }^{10 \mathrm{c} .65}$

Now, elimination reactions provide the few examples that exist of productstability control. Hence, the tentative proposal is made that product-stability control is important only when the differences in product stability are at least about $2 \mathrm{kcal}$ $\mathrm{mol}^{-1}$ (corresponding to the presence of about $95 \%$ of the most stable product, at equilibrium at $25^{\circ} \mathrm{C}$ ).

\section{Conclusions}

Contrary to intuitive expectations, product-stability control is rather rare in organic reactions. In kinetically-controlled organic reactions, it seems that productstability differences influence product composition only if the differences are at least about $2 \mathrm{kcal} \mathrm{mol}^{-1}$. Apparently, available theories of chemical reactivity do not satisfactorily explain these findings. Perhaps, much further work is needed.

${ }^{65}$ E. I. Eliel, ref. 7, pp. 139, 236, 280, 303. 